\title{
Article \\ Alteration of Extracellular Matrix Components in the Anterior Pituitary Gland of Neonatal Rats Induced by a Maternal Bisphenol A Diet during Pregnancy
}

\author{
Bumpenporn Sanannam ${ }^{1}$, Sasikarn Looprasertkul ${ }^{1,2}$, Songphon Kanlayaprasit ${ }^{3}$, Nakarin Kitkumthorn ${ }^{4}$, \\ Tewarit Sarachana ${ }^{5,6}$ and Depicha Jindatip $1,2,6, *$ (D)
}

1 Department of Anatomy, Faculty of Medicine, Chulalongkorn University, 1873 Rama 4 Rd., Wangmai, Pathumwan, Bangkok 10330, Thailand; bumpenporn.s@student.chula.ac.th (B.S.); sasikarn.loo@alumni.chula.ac.th (S.L.)

2 Department of Anatomy, Division of Histology and Cell Biology, School of Medicine, Jichi Medical University, 3311-1 Yakushiji, Shimotsuke 329-0498, Tochigi, Japan

3 Department of Clinical Chemistry, Faculty of Allied Health Sciences, Chulalongkorn University, Bangkok 10330, Thailand; songphon.ka@student.chula.ac.th

4 Department of Oral Biology, Faculty of Dentistry, Mahidol University, Payathai Rd., Ratchathewi, Bangkok 10400, Thailand; nakarin.kit@mahidol.ac.th

5 Age-Related Inflammation and Degeneration Research Unit, Department of Clinical Chemistry, Faculty of Allied Health Sciences, Chulalongkorn University, 154 Rama 1 Rd., Wangmai, Pathumwan, Bangkok 10330, Thailand; tewarit.sa@chula.ac.th

check for updates

Citation: Sanannam, B.; Looprasertkul, S.; Kanlayaprasit, S.; Kitkumthorn, N.; Sarachana, T.; Jindatip, D. Alteration of Extracellular Matrix Components in the Anterior Pituitary Gland of Neonatal Rats Induced by a Maternal Bisphenol A Diet during Pregnancy. Int. J. Mol. Sci. 2021, 22, 12667. https://doi.org/ $10.3390 /$ ijms 222312667

Academic Editor: Hideko Sone

Received: 18 October 2021

Accepted: 22 November 2021

Published: 23 November 2021

Publisher's Note: MDPI stays neutral with regard to jurisdictional claims in published maps and institutional affiliations.

Copyright: (c) 2021 by the authors. Licensee MDPI, Basel, Switzerland. This article is an open access article distributed under the terms and conditions of the Creative Commons Attribution (CC BY) license (https:/ / creativecommons.org/licenses/by/ $4.0 /)$.
6 Systems Neuroscience of Autism and Psychiatric Disorders (SYNAPS) Research Unit, Department of Clinical Chemistry, Faculty of Allied Health Sciences, Chulalongkorn University, Bangkok 10330, Thailand

* Correspondence: depicha.j@chula.ac.th; Tel.: +66-2-256-4281

\begin{abstract}
The extracellular matrix (ECM) plays crucial roles in the anterior pituitary gland via the mechanism of cell-ECM interaction. Since bisphenol A (BPA), a well-known endocrine disruptor, can cross through the placenta from mother to fetus and bind with estrogen receptors, cell populations in the neonatal anterior pituitary gland could be the target cells affected by this chemical. The present study treated maternal rats with $5000 \mu \mathrm{g} / \mathrm{kg}$ body weight of BPA daily throughout the pregnancy period and then investigated the changes in ECM-producing cells, i.e., pericytes and folliculostellate (FS) cells, including their ECM production in the neonatal anterior pituitary at Day 1 . We found that pericytes and their collagen synthesis reduced, consistent with the increase in the number of FS cells that expressed several ECM regulators-matrix metalloproteinase (MMP) 9 and the tissue inhibitors of metalloproteinase (TIMP) family. The relative MMP9/TIMP1 ratio was extremely high, indicating that the control of ECM homeostasis was unbalanced. Moreover, transmission electron microscopy showed the unorganized cell cluster in the BPA-treated group. This study revealed that although the mother received BPA at the "no observed adverse effect" level, alterations in ECM-producing cells as well as collagen and the related ECM balancing genes occurred in the neonatal anterior pituitary gland.
\end{abstract}

Keywords: anterior pituitary gland; bisphenol A; collagen; endocrine-disrupting chemicals; extracellular matrix; folliculostellate cell; matrix metalloproteinase; neonate; pericyte; tissue inhibitors of metalloproteinase

\section{Introduction}

Bisphenol A (BPA) is acknowledged as one of the most common endocrine-disrupting chemicals and is able to bind to estrogen receptors [1]. BPA is primarily used as a monomer of polycarbonate plastics and epoxy resin production found in many consumer products and can cause food contact and contamination [2]. Since BPA has the potential to transfer through umbilical blood circulation and fetal metabolization of this chemical is limited, this chemical is detected at a high concentration in both the placenta and fetus [3]. Exposure 
to BPA during the embryonic stage was mentioned in the decline of reproductive ability in adulthood, abnormal estrus cycles, and decreases in LH serum $[4,5]$. Although these studies did not directly investigate the hypothalamo-hypophyseal level, the results indicate that the anterior pituitary gland is also a BPA target tissue.

The anterior pituitary gland is a major organ that plays an important role in the endocrine system. This gland produces many essential hormones related to body homeostasis. Cell populations of the anterior pituitary gland are composed of five types of hormoneproducing cells and nonhormone-producing cells, i.e., folliculostellate (FS) cells, endothelial cells, pericytes, novel desmin-immunopositive perivascular cells and macrophages [6]. In addition to cell populations in the pituitary gland, the extracellular matrix (ECM) diffuses in the areas around cell clusters and the perivascular space [7], and our previous studies found that Collagen types I and III in the rat anterior pituitary gland are produced mainly by pericytes facilitated by FS cells [8,9]. Moreover, these two cell types expressed some of the matrix metalloproteinase (MMP) and tissue inhibitors of metalloproteinase (TIMP) genes that maintain ECM equilibrium [10,11].

The effects of BPA on the alteration of ECM components and characteristics have been documented in some organ conditions, such as liver fibrosis and cardiovascular function [12,13]. In the anterior pituitary gland, the adverse effects of BPA on hormoneproducing cells and their secretion have been reported in several studies. Publications have revealed that prenatal BPA administration at doses up to the "no observed adverse effect" level (NOAEL) is related to increases in the proliferation of progenitor cells and gonadotrophs, as well as the mRNA levels of the gonadotropin-releasing hormone receptor, follicle-stimulating hormone and luteinizing hormone [14,15]. In addition, other studies have reported the elevation of fetal serum thyroid-stimulating hormone secretion and the reduction of growth hormones in offspring in response to BPA exposure [16,17]. However, BPA-induced ECM changes, especially in the anterior pituitary of neonates, have not been investigated. Therefore, the present study performed immunohistochemistry to investigate the number and characteristics of ECM-producing cells, i.e., pericytes and FS cells, including the distribution and intensity of collagen staining. Gene expression of collagen Type I and III, MMP9 and the TIMP family produced by these ECM-producing cells was evaluated. Moreover, transmission electron microscopy revealed cell organization in the anterior pituitary gland of both control and BPA-treated neonatal rats.

\section{Results}

\subsection{Effects of BPA at the NOAEL Level on ECM-Producing Cells}

NG2 was used as a pericyte marker, which was observed in both the anterior and posterior lobes. Focusing on the anterior pituitary lobe, NG2 immunopositive cells were closely related to the capillaries (Figure 1A-D). The number of pericytes and the intensity of immunosignals significantly decreased in the BPA-treated group $(405.6 \pm 23.96$ and $9665 \pm 17.87$, respectively) compared with the control group (668.0 \pm 89.15 and $9756 \pm 27.02$, respectively) (Figure 1E,F).

As pericytes and FS cells interact with each other for ECM production in the anterior pituitary gland, the number of FS cells was also examined by immunohistochemistry. Anti-S100 antibody is commonly used as a marker of FS cells in several adult rodents. However, immunoreactivity could not be observed in the anterior lobe of rats at postnatal Day 1 (Figure 2A,B). Therefore, aldolase C, a novel FS cell marker, was selected for FS cell identification instead of S100. The preliminary results showed that FS cells were intensely stained by anti-aldolase $\mathrm{C}$ antibody in the intact neonatal anterior pituitary glands (Figure $2 \mathrm{C}, \mathrm{D}$ ). In the present study, increases in the number of aldolase $\mathrm{C}$ immunopositive cells and immunoreactive intensity were observed in the BPA-treated group (1206 \pm 266.5 and $9368 \pm 58.62$, respectively) compared with the control group $(694.8 \pm 202.5$ and $9068 \pm 20.84$, respectively) (Figure 3). 


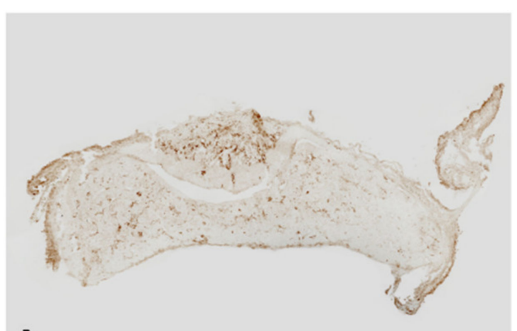

A
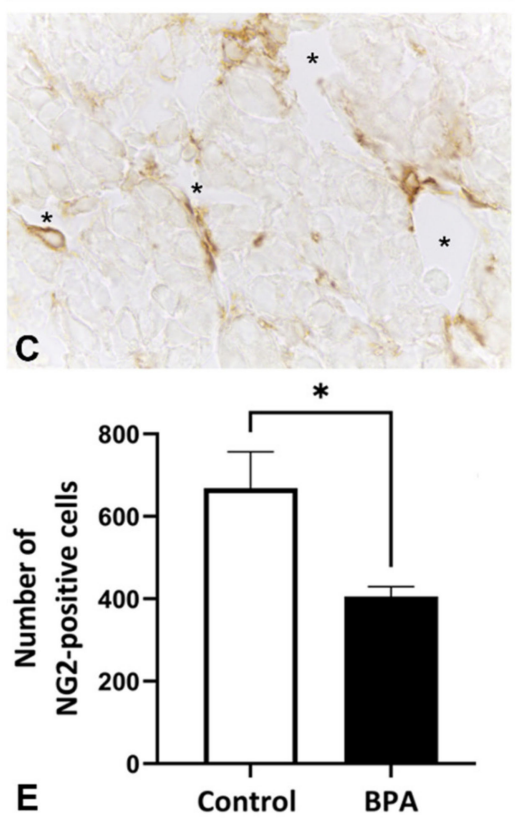

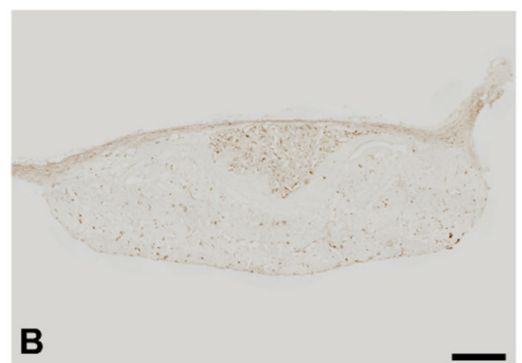

B
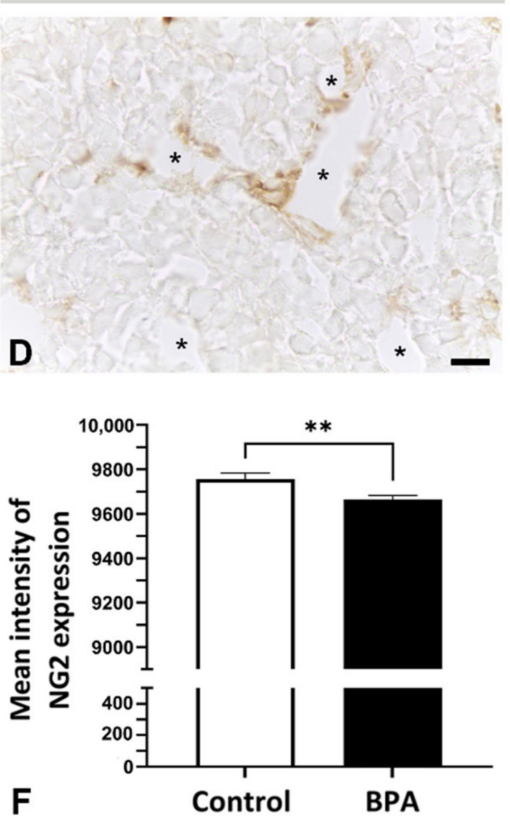

Figure 1. Immunohistochemistry of NG2 on postnatal Day 1 in the anterior pituitary glands of control rats $((\mathbf{A}, \mathbf{C})$ : higher magnification view of $(\mathbf{A}))$ and BPA-treated rats $((\mathbf{B}, \mathbf{D})$ : higher magnification view of (B)). The number (E) and mean intensity (F) of NG2-positive cells decreased in the BPA-treated group. Note: the capillary lumens (asterisks), ${ }^{*} p<0.05,{ }^{* *} p<0.01$. Scale bars: $100 \mu \mathrm{m}(\mathbf{A}, \mathbf{B}) ; 10 \mu \mathrm{m}$ $(\mathrm{C}, \mathrm{D})$.

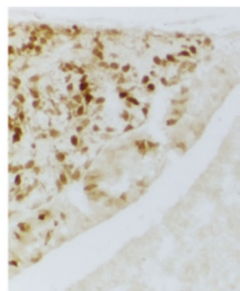

A

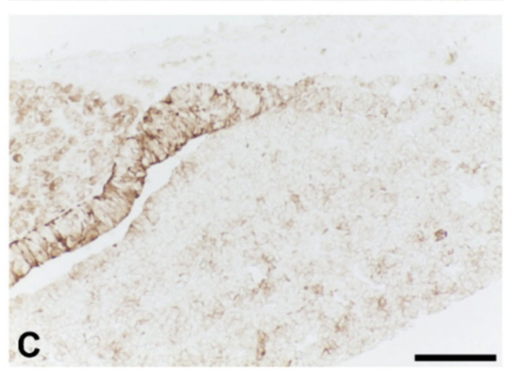

B

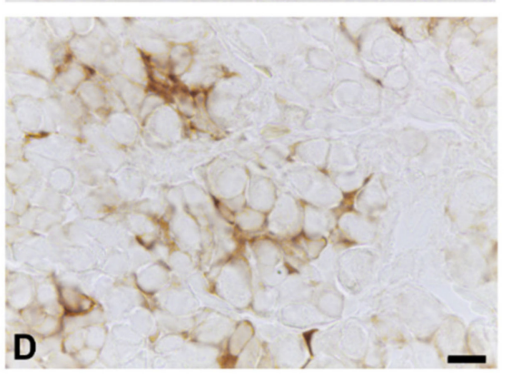

Figure 2. Immunohistochemistry of $S 100((\mathbf{A}, \mathbf{B})$ : higher magnification view of $(\mathbf{A}))$ and aldolase $C((C, D)$ : higher magnification view of $(C))$ on postnatal Day 1 in the anterior pituitary glands of control rats. Scale bars: $100 \mu \mathrm{m}(\mathbf{A}, \mathbf{C}) ; 10 \mu \mathrm{m}(\mathbf{B}, \mathbf{D})$. 

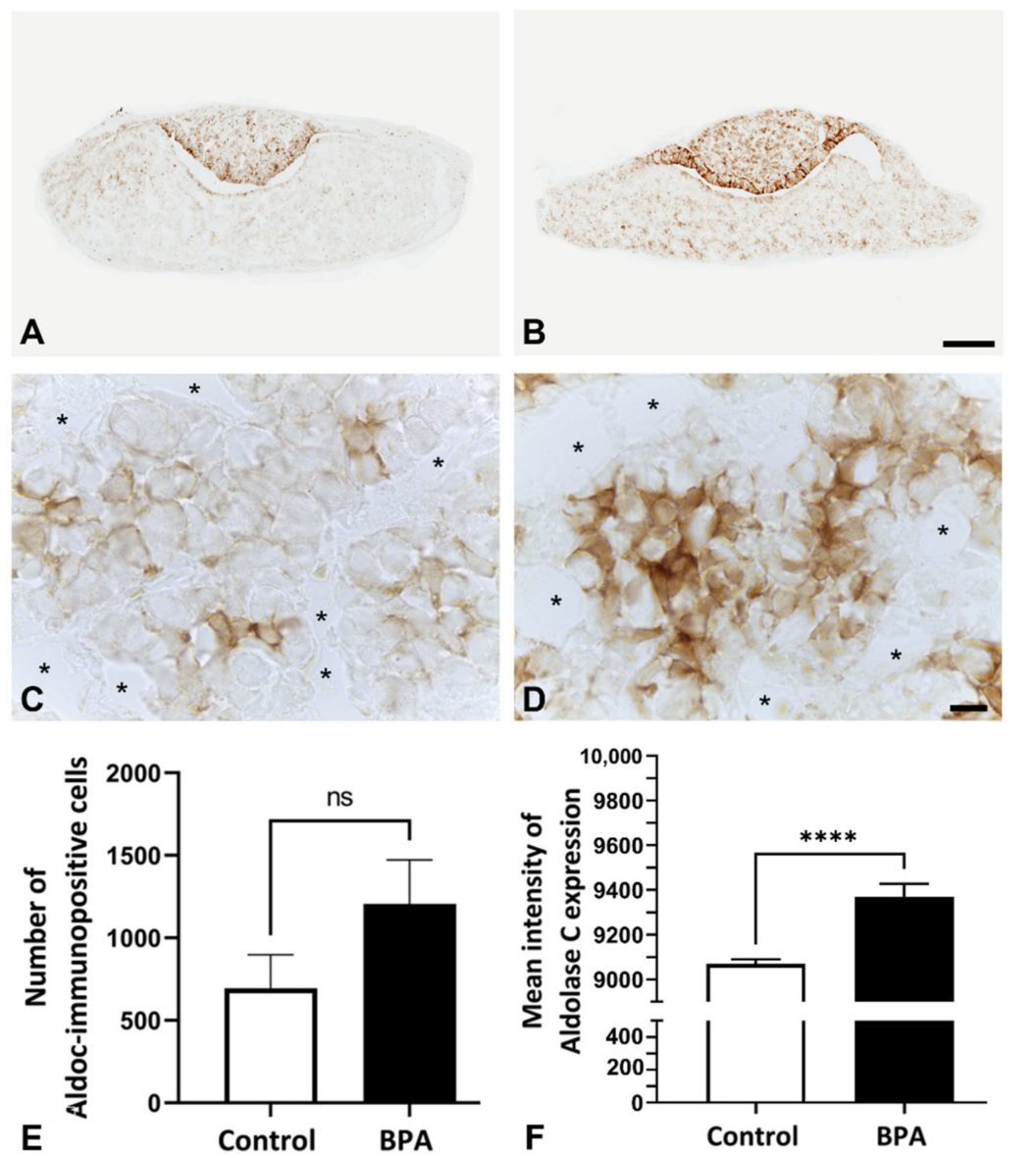

Figure 3. Immunohistochemistry of aldolase $C$ on postnatal Day 1 in the anterior pituitary glands of control rats $((\mathbf{A}, \mathbf{C})$ : higher magnification view of $(\mathbf{A}))$ and BPA-treated rats $((\mathbf{B}, \mathbf{D})$ : higher magnification view of $(\mathbf{B}))$. Number $(\mathbf{E})$ and mean intensity $(\mathbf{F})$ of aldolase $C$ immunopositive cells in the control and BPA-treated groups. Note: the capillary lumens (asterisks). No significant differences (ns), ${ }^{* * * *} p<0.0001$. Scale bars: $100 \mu \mathrm{m}(\mathbf{A}, \mathbf{B}) ; 10 \mu \mathrm{m}(\mathbf{C , D})$.

\subsection{Alterations of ECM Components Focusing on Collagens}

Collagen Types I and III were examined by using RT-qPCR analysis. The mRNA expression of both col1a1 and col3a1 was downregulated in the BPA-treated group. In particular, collagen Type I showed a significant decrease in the BPA-treated group compared with the control (Figure 4).

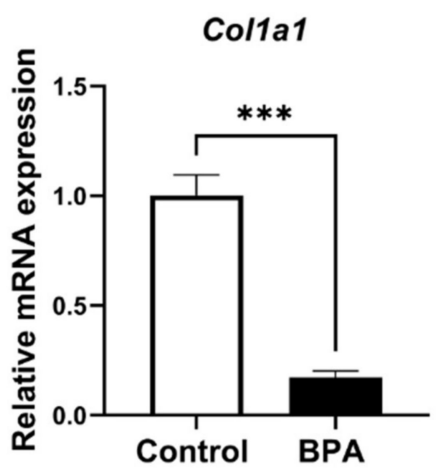

A

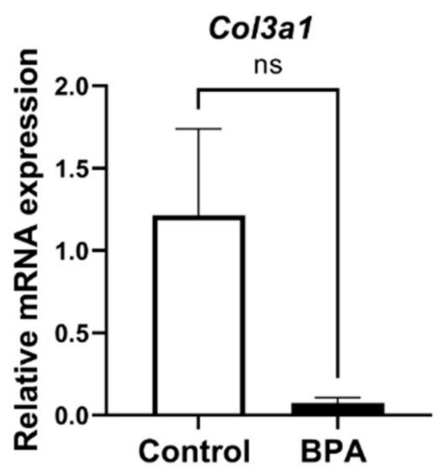

B

Figure 4. Col1a1 (A) and col3a1 (B) gene expression in the control and BPA-treated groups. Note: no significant differences (ns), ${ }^{* * *} p<0.0001$. 
In addition, the immunohistochemistry of collagen Type I in the gland was also observed under light microscopy. The results showed that the pattern of collagen distribution in BPA rats seemed to be less than the pattern of collagen distribution in the control rats (Figure 5A-D). The immunoreactive intensity of collagen was decreased in the BPA group (Figure 5E).

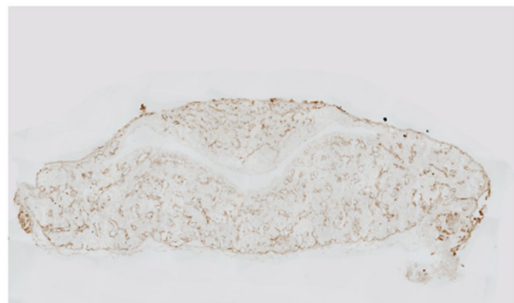

A

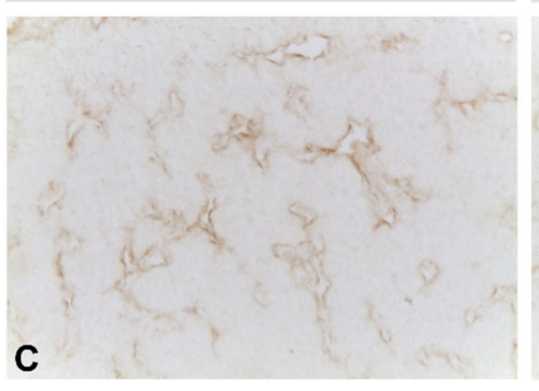

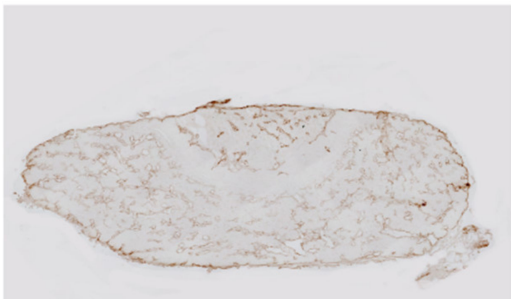

B

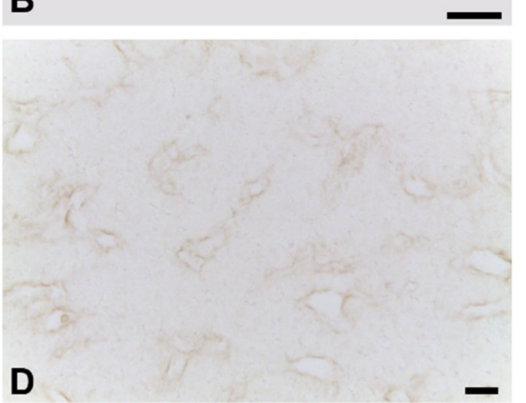

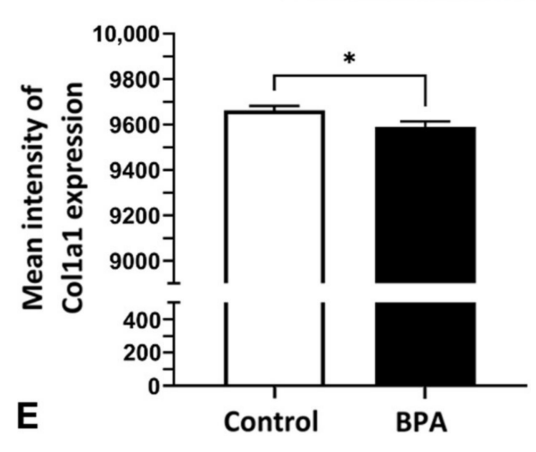

Figure 5. Immunohistochemistry of collagen Type I on postnatal Day 1 in the anterior pituitary glands of control rats $((\mathbf{A}, \mathbf{C})$ : higher magnification view of $(\mathbf{A}))$ and BPA-treated rats $((\mathbf{B}, \mathbf{D})$ : higher magnification view of $(\mathbf{B})$ ). Mean intensity in the control and BPA-treated groups (E). Note: ${ }^{*} p<0.05$. Scale bars: $100 \mu \mathrm{m}(\mathbf{A}, \mathbf{B}) ; 10 \mu \mathrm{m}(\mathbf{C}, \mathbf{D})$.

\subsection{Alterations of ECM Balancing Regulators}

ECM balancing, in both general and pathological conditions, is involved in MMP and TIMP interactions. Therefore, MMP9, which is produced by FS cells and is one of the major MMPs in the anterior pituitary gland, was examined. The results revealed that MMP9 mRNA expression levels showed statistically significant differences (Figure 6). For the TIMP family, mRNA expression of TIMP1, TIMP2, TIMP3 and TIMP4 was also detected in the glands of both the control and BPA-treated groups. The results showed that no difference in TIMP1 was detectable between the two groups, whereas the expression levels TIMP2 and TIMP3 mRNA were upregulated in BPA-treated rats. Note that the mRNA level of TIMP4 was also increased, but the difference between groups was not statistically significant (Figure 7). In addition, the relative ratio of MMP9/TIMP1 is shown in Figure 8. 


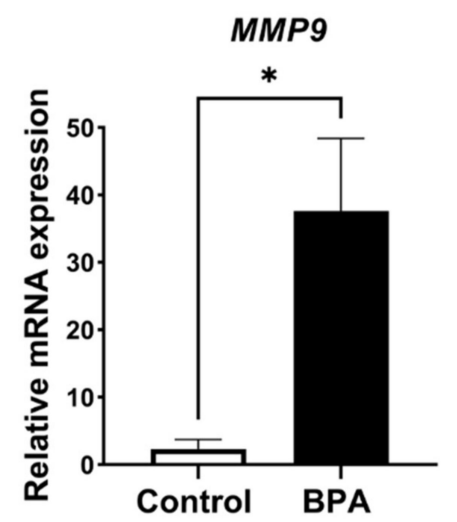

Figure 6. MMP9 mRNA expression in the control and BPA-treated groups. Note: ${ }^{*} p<0.05$.

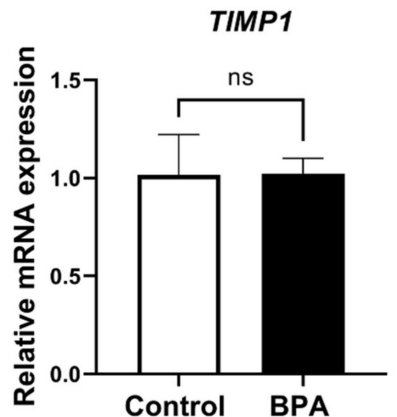

A

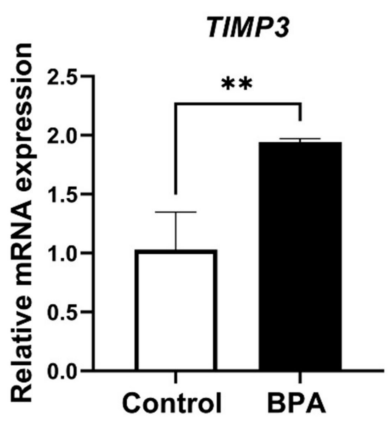

C

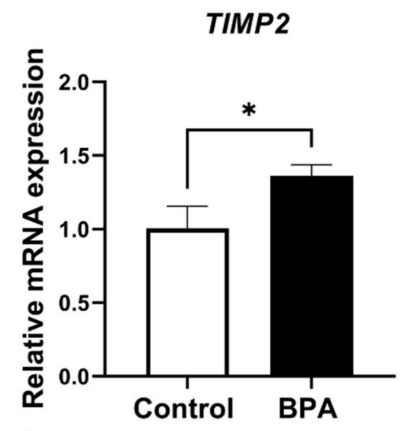

B

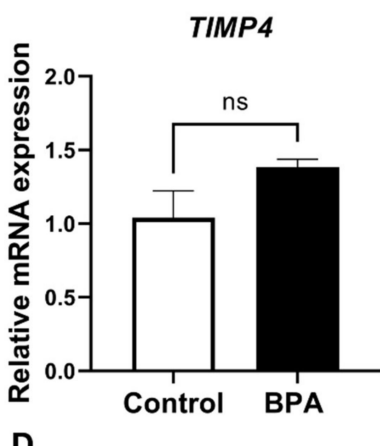

Figure 7. TIMP 1 (A), TIMP 2 (B), TIMP3 (C) and TIMP 4 (D) gene expression in the control and BPA-treated groups. Note: no significant differences (ns), ${ }^{*} p<0.05$ and ${ }^{* *} p<0.01$.

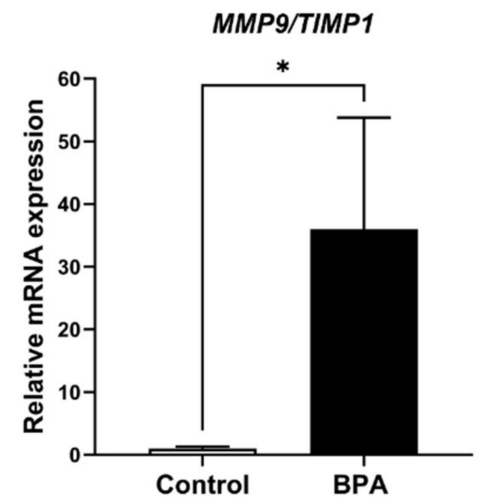

Figure 8. Relative MMP9/TIMP1 ratio of mRNA expression in the control and BPA-treated groups. Note: ${ }^{*} p<0.05$. 


\subsection{Tissue Organization Observed by Transmission Electron Microscopy}

In control rats, the anterior pituitary gland of the neonates demonstrated a cell cluster formation encircled by the fenestrated capillary network, while the cells of BPA-treated rats were not well organized in forming the cluster, as was the case in the control group (Figure 9). The morphology of pericytes and FS cells was also observed, although there was no difference in fine structure between the control and BPA-treated rats.
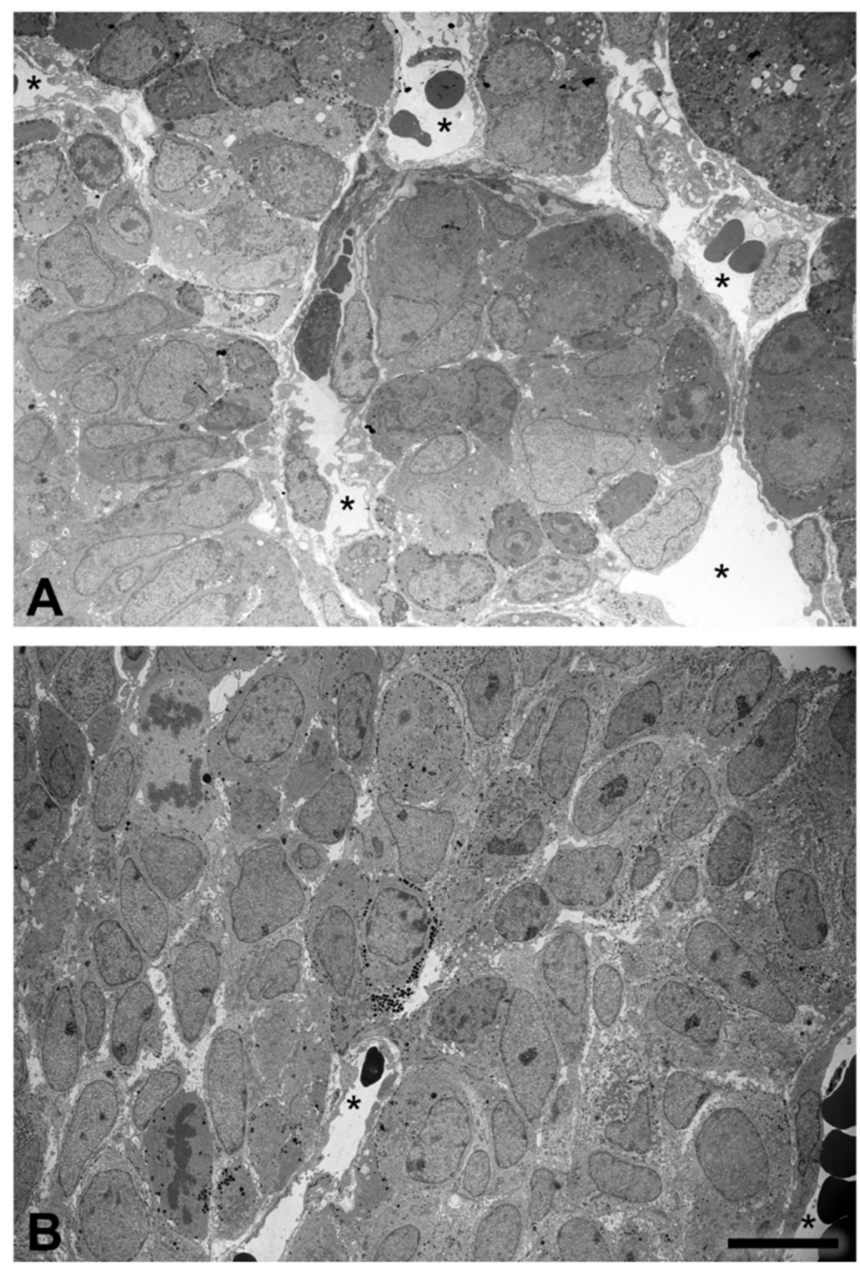

Figure 9. Transmission electron microscopy of cell cluster organization in the neonatal anterior pituitary gland of the control (A) and BPA-treated groups (B). Note: the capillary lumens (asterisks). Scale bar: $10 \mu \mathrm{m}$.

\section{Discussion}

The present study revealed that maternal BPA exposure affects ECM-producing cells and their activities in the neonatal anterior pituitary gland. The number of pericytes, NG2 immunosignal intensity and collagen immunohistochemical staining decreased, consistent with the decrease in collagen mRNA expression. In addition, increases in FS cell numbers and their staining intensity correlated with alterations in ECM balancing regulators. Moreover, transmission electron microscopic visualization revealed predominantly unformed cluster characteristics in the anterior pituitary gland of prenatal BPA exposure rats.

Pericytes in the anterior pituitary gland are known as synthesizers of collagen Types I and III from postnatal development to adulthood $[8,18]$. Our previous study demonstrated that the collagen activity of pituitary pericytes was downregulated in prolactinoma rats that were treated with diethylstilbestrol (DES) for 3 months [19]. The present study revealed the suppressive effect of maternal BPA exposure on collagen expression and the number of pericytes in neonatal rats (Figures 1,4 and 5). There has been a report of the 
similarity in chemical structure between DES and BPA, showing that they are classified as estrogen-like endocrine-disrupting chemicals and can bind to estrogen receptors that induce hyperprolactinemia [20]. As pericytes also contain estrogen receptors [21], we presume that the effects of BPA on collagen suppression occur via this pathway. Although BPA can induce prolactinoma with high proliferation of several cell types [22], our present study used the NOEAL of BPA, which did not reach the pathological angiogenesis of tumors. Therefore, the number of vascular pericytes in this study was not high, as is the case with DES administration. However, a small number of pericytes resulting in collagen reduction is reasonable.

A specific marker that is commonly used for detecting FS cells in the anterior pituitary gland is S100. In our preliminary study, S100 staining was not observed in any area on Day 1 of age in rats (Figure 2A,B). This result resembled the study of Wada et al. (2014), which reported that S100 immunopositive signals were first identified on the anterior pituitary on around postnatal Day 15 [23]. Aldolase C was recently reported as a novel marker of FS cells in adult mouse pituitary glands [24]. Interestingly, the present study succeeded in identifying FS cells in the newborn rat pituitary by using this anti-aldolase $C$ antibody (Figure 2C,D). We hypothesized that the differential protein marker expression is due to the highly dynamic characteristics of FS cells during pituitary development. Therefore, this finding could help researchers investigate FS cells at an early postnatal stage through to adulthood in rat strains under conventional light microscopic levels.

Since FS cells also present estrogen receptors [25], endocrine-disrupting chemicals could induce changes in the properties of these cells. In the present study, BPA had significant positive effects on the cell number and immunostaining intensity of FS cells in contrast to pericytes. Brannick et al. (2012) mentioned that the use of low BPA doses in mice during the prenatal stage resulted in an increase in the cell proliferation of gonadotrophs and SOX2-expressing progenitor cells in the neonatal anterior pituitary gland [14]. Several publications have reported the expression of progenitor or stem cell markers in FS cells, including SOX2 [26-28]. These data suggest that FS cells in our present study are also one of the proliferating cell populations that increase in number and activity in prenatal BPAtreated offspring. In addition, it is possible that the alterations in FS cells might involve other indirect adverse effects, such as local hormones in the gland, since FS cells present several pituitary hormone receptors [29]. For example, Ahmed (2016) revealed serum TSH elevation in 20-day-old fetuses after treating maternal rats with BPA throughout gestation Days 1 to 20 [16]. Similar to the study from Brokken et al. (2005), they found that the FS cell line contained TSH receptors, and these cells expressed several cell proliferation-related genes that were regulated by TSH [30]. However, the level of TSH secretion induced by BPA remains controversial. Brannick et al. (2012) reported that TSH mRNA in thyrotrophs was not changed in postnatal Day 1 mice exposed to maternal BPA during gestation Days 10.5 to 18.5 [14]. Therefore, the effects of local pituitary hormones on FS cells in response to BPA exposure need to be clarified in further studies.

Pituitary pericytes require a paracrine factor, TGF $\beta 2$, to be released from FS cells to synthesize collagens [9]. In addition, the ECM proteolytic enzyme and ECM proteolytic enzyme inhibitors were detected in either pericytes or FS cells, i.e., MMP9 and the TIMP family. Ilmiawati et al. (2012) demonstrated that FS cells on laminin expressed MMP9, and then their MMP9 returned to promote the proliferation of FS cells themselves [10]. These data support our present findings of numerous FS cells (Figure 3) and a significant elevation of MMP9 levels (Figure 6). Thus, autocrine stimulation would be considered an additional route of FS cell proliferation triggered by BPA. ECM turnover is regulated via MMP-TIMP interactions in rat and human anterior pituitary glands. There are four subtypes of the TIMP family that act as tissue inhibitors of MMPs. A publication reported that TIMP1, TIMP2 and TIMP3 mRNAs were expressed mainly in FS cells, whereas TIMP4 was not detectable in any cells of the anterior pituitary gland of adult rats [11]. Surprisingly, we found the expression of all TIMPs, including TIMP4, in neonatal rats of both the control and BPA-treated groups. However, TIMP4-producing cells were not investigated in the present study. Although 
all TIMPs in the BPA-treated group tended to increase to regulate ECM degradation (Figure 7), the $M M P$ level remained high (Figure 6). We hypothesized that even though the expression of TIMPs was elevated, it was not high enough to inhibit the increasing level of MMPs. Moreover, the concept of the MMP/TIMP ratio, which demonstrates ECM equilibrium, might be useful for explaining this phenomenon [31]. In Figure 8, the high relative MMP9/TIMP1 ratio, which might occur with other MMPs/TIMPs, in the BPA-treated group could indicate an ECM imbalance. Moreover, transmission electron microscopy (Figure 9) showed that BPA also affected cell cluster formation in the anterior pituitary gland.

\section{Materials and Methods}

\subsection{Animal and Treatment}

Wistar rats at 8 weeks of age were purchased from the National Laboratory Animal Center (NLAC), Thailand. Animals were housed under standard temperature $\left(21 \pm 1^{\circ} \mathrm{C}\right)$ and humidity conditions (30-70\%) with a 12-h light/dark cycle at Chulalongkorn University Laboratory Animal Center. After normal inbreeding, maternal rats were divided into 2 groups. The amount of daily treated BPA was calculated from the maternal weight each day. The rats were given food and RO-UV water ad libitum. These rats were given $5000 \mu \mathrm{g} / \mathrm{kg}$ BW of BPA daily [32-35] (Cat. No. 239658, Sigma-Aldrich, St. Louis, MO, USA) in absolute ethanol (Cat. No. 1000983, Merck Millipore, Darmstadt, Germany) and corn oil by oral administration throughout their pregnancy periods (approximately 21 days) as described in our previously published study [33]. This dose was selected based on the "no observed adverse effect" level (NOAEL) for BPA determined by the US Food and Drug Administration (FDA) and the European Food Safety Authority (EFSA). A mixture of absolute ethanol with corn oil was applied as the vehicle control treatment. All animal experimental procedures and research protocols were approved by the Chulalongkorn University Animal Care and Use Committee (Animal Use Protocol No. 1773011) and the Animal Ethical Committee of the Faculty of Medicine (010/2562), Chulalongkorn University, Bangkok, Thailand.

\subsection{Tissue Collection}

After parturition, postnatal Day 1 rats were euthanized by sodium pentobarbital via intraperitoneal injection. The rats were then decapitated, followed by freezing on ice. The pituitary gland was promptly removed with the aid of a stereomicroscope (SMZ800 Zoom; Nikon, Japan).

\subsection{Immunohistochemistry}

Five neonatal pituitary glands from each group were immediately immersed in $4 \%$ PFA in 0.1 M PB (pH 7.4) overnight, followed by 30\% sucrose (Cat. No. S0111, TCI, Tokyo, Japan) in 0.1 M PB ( $\mathrm{pH} 7.4$ ) for $48 \mathrm{~h}$. Glands were then embedded in Tissue-tek (Cat. No. 4583, Sakura Finetechnical, Tokyo, Japan) and stored at $-80^{\circ} \mathrm{C}$. Frontal $6 \mu \mathrm{m}$ cryosections were cut by a cryostat (CM1950; Leica Biosystems, Nussloch, Germany) for immunohistochemistry. To block nonspecific signals, sections were incubated in phosphate-buffered saline (PBS) containing $2 \%$ normal goat serum (Cat. No. S-1000, Vector Laboratories, Burlingame, CA, USA). Anti-NG2 rabbit polyclonal antibody (pericyte marker, diluted 1:600; Cat. No. AB5320, Merck Millipore, Darmstadt, Germany), anti-S100 rabbit polyclonal antibody (FS cell marker, diluted 1:1000; Cat. No. Z0311, Agilent DAKO, Santa Clara, CA, USA), anti-aldolase $C$ rabbit polyclonal antibody (novel FS cell marker, diluted 1:200; Cat. No. AB_2571658, Frontier Institute Co., Ltd., Hokkaido, Japan) or anti-collagen type I rabbit polyclonal antibody (diluted 1:400; Cat. No. ab34710, Abcam, Cambridge, UK) were incubated overnight at room temperature. After primary antibody incubation, tissues were incubated in biotinylated anti-rabbit IgG (diluted 1:150; Cat. No. BA-1000, Vector Laboratories, Burlingame, CA, USA) at $30{ }^{\circ} \mathrm{C}$ for $30 \mathrm{~min}$. The $\mathrm{ABC}$ method (Cat. No. PK-4000, Vector Laboratories, Burlingame, CA, USA) and 3,3'-diaminobenzidine as the 
substrate (Cat. No. D5637, DAB; Dojindo Laboratories, Kumamoto, Japan) were applied to demonstrate the signal expression. Five random fields at $40 \times$ magnification were captured by light microscopy (DM1000; Leica Microsystems, Wetzlar, Germany). The number of immune-positive cells and the immunostaining intensity were evaluated by ImageJ software version 1.52a (Wayne Rasband, National Institutes of Health, Bethesda, MD, USA) and ZEN software version 3.0 (Blue edition, Carl Zeiss Microscopy, Oberkochen, Germany).

\subsection{Determination of $m R N A$ Expression by RT-qPCR}

Three rats per group were sacrificed for this experiment. First, the posterior pituitary lobe was removed during dissection. The anterior pituitary tissues were then quickly put into a tube containing RNAlater (AM7024, Thermo Fisher Scientific Inc., Rockford, IL, USA). These glands were stored at $-80^{\circ} \mathrm{C}$ until use. Total RNA of the anterior pituitary gland was isolated by using TRIzol's protocol (Cat. No. 15596026, Invitrogen, Carlsbad, CA, USA). Next, cDNA synthesis was performed by using a RevertAid First-Strand cDNA Synthesis Kit (Cat. No. K-1621, Thermo Fisher Scientific Inc., Rockford, IL, USA) according to the manufacturer's protocol. The stock of cDNA was stored at $25 \mathrm{ng} / \mu \mathrm{L}$. One microliter of the $5 \mathrm{ng} / \mu \mathrm{L}$ cDNA template was used for qPCR analysis by mixing with $2 X$ Greenstar Master Mix (Cat. No. K-6253, Bioneer, Daejeon, Korea), both forward and reverse primers, and ultrapure water. The mixture was then incubated in a CFX 96 thermocycler (Bio-Rad Laboratories, Hercules, CA, USA). Amplification was performed according to these steps: an initial denaturing step at $95{ }^{\circ} \mathrm{C}$ for $15 \mathrm{~min}$, followed by 45 cycles of $10 \mathrm{~s}, 95{ }^{\circ} \mathrm{C}$ as the denaturing step and annealing/extension for $30 \mathrm{~s}$ at $55^{\circ} \mathrm{C}$. Melting curve data were considered to confirm product formation $\left(65\right.$ to $\left.95^{\circ} \mathrm{C}\right)$. The expression was calculated using the $2^{-\Delta \Delta \mathrm{Ct}}$ method; $18 \mathrm{~S}$ ribosomal RNA (RN18S) was used as the internal control. Primers for PCR (Table 1) were explored by using the USCS Genome Browser (https:/ / genome. ucsc.edu./ (accessed on 10 June 2019)) and Ensembl (https:/ / asia.ensembl.org/inderx.html (accessed on 10 June 2019)). The sequences of primers were created by Primer3 software (http:/ / bioinfo.ut.ee/primer3-0.4.0/ (accessed on 10 June 2019)).

Table 1. Primers of the targeted genes.

\begin{tabular}{|c|c|c|}
\hline Genes & Forward Primer $\left(5^{\prime}>-3^{\prime}\right)$ & Reverse Primer $\left(5^{\prime}>-3^{\prime}\right)$ \\
\hline Collagen type 1 (Col1a1) & CCTGACGCATGGCCAAGA & CTGGGCAGAAAGGACAGCA \\
\hline Collagen type 3 (Col3a1) & TGCCACCCTGAACTCAAGAG & CACCAGCATATGTCCACCA \\
\hline Matrix metalloproteinase 9 (MMP9) & AGAGCGTTACTCGCTTGGA & CTGCAGGAGGTCATAGGTCA \\
\hline Tissue inhibitor of metalloproteinase 1 (TIMP1) & CTGGCATCCTCTTGTTGCT & AGGTGGTCTCGATGATTTCTG \\
\hline Tissue inhibitor of metalloproteinase 2 (TIMP2) & GACGTTGGAGGAAAGAAGGA & GGCTCTTCTTCTGGGTGATG \\
\hline Tissue inhibitor of metalloproteinase 3 (TIMP3) & TGGGAAAGAAGCTGGTGAA & CACATGGGGCATCTTACTGA \\
\hline Tissue inhibitor of metalloproteinase 4 (TIMP4) & CACGCCATTTGACTCTTCTC & CTCCCAGGGCTCAATGTAGT \\
\hline 18S Ribosomal RNA (RN18S) & CTGGATACCGCAGCTAGGAA & GAATTTCACCTCTAGCGGCG \\
\hline
\end{tabular}

\subsection{Transmission Electron Microscopic (TEM)}

TEM was performed to evaluate the changes in cell cluster organization. Three collected pituitary glands per group were fixed with $2 \%$ glutaraldehyde (Cat. No. 16220, EMS, Hatfield, PA, USA) in 0.1 M PB (pH 7.4) for $2 \mathrm{~h}$, followed by 4 washes with PB. Next, tissues were treated with $1 \%$ osmium tetroxide $\left(\mathrm{OsO}_{4}\right.$; Cat. No. 19110, EMS, Hatfield, PA, USA) on ice for $90 \mathrm{~min}$. After postfixation in $\mathrm{OsO}_{4}$, specimens were washed with cold distilled water, dehydrated by an alcohol series (Cat. No. 1000983, Merck Millipore, Darmstadt, Germany) and propylene oxide (Cat. No. 807027, Merck Millipore, Darmstadt, Germany). Next, specimens were embedded in epoxy resin and polymerized at $60^{\circ} \mathrm{C}$. The specimen resin blocks were cut into ultrathin sections at $70 \mathrm{~nm}$ thickness by an ultramicrotome (EM UC7, Leica, Vienna, Austria) and stained with lead citrate (Cat. No. 178000, EMS, Hatfield, PA, USA) 
and uranyl acetate (Cat. No. 22400, EMS, Hatfield, PA, USA). Ultrastructural changes in cells and cluster organization were examined under a transmission electron microscope (JEM-1400PLUS; JEOL, Tokyo, Japan).

\subsection{Statistical Analysis}

The results are presented as the mean \pm standard error of the mean (SEM). Student's $t$-test was used to compare differences between groups, which were considered statistically significant at a value of $p<0.05$. The analyses were calculated using GraphPad Prism 9.2.0 (GraphPad Software, Inc., San Diego, CA, USA) and IBM SPSS Statistics version 23 (SPSS, Inc., Armonk, NY, USA).

\section{Conclusions}

The present study revealed that even though fetuses received BPA at a dose without observed adverse effects, alterations in ECM-producing cell properties and ECM products, as well as related ECM balancing genes and cell cluster formation, were detectable in the anterior pituitary gland. The findings of this study support the hypothesis that the prenatal stage is highly sensitive to endocrine-disrupting chemicals because this stage is one of the critical periods during development. However, the limitations of the present study are the use of a single dose of BPA and one-period evaluation. In addition, there are several types of bisphenols used instead of BPA and labeled on products as BPA-free nowadays. Awareness of the harm of these bisphenols should also be raised. For further directions, the effects of bisphenol derivatives such as BPF or BPS on ECM components in the anterior pituitary gland at various doses and times during gestation until the postnatal period need to be verified. Moreover, the numbers of ECM-related cells in connection with the numbers of hormone-producing cells, as well as their three-dimensional physical interactions, should also be included in the further studies. These data will provide a better understanding of ECM's controlling function in the anterior pituitary gland under bisphenol derivative administration.

Author Contributions: Conceptualization, D.J. and T.S.; methodology, D.J.; software, B.S. and S.L.; validation, D.J., T.S. and N.K.; formal analysis, B.S. and S.L.; investigation, D.J.; resources, D.J., T.S. and N.K.; writing-original draft preparation, B.S. and D.J.; writing - review and editing, S.K. and D.J.; visualization, S.L., S.K. and D.J.; supervision, D.J. and T.S. All authors have read and agreed to the published version of the manuscript.

Funding: This work was supported by the Ratchadapiseksompotch Fund, Department of Anatomy, Faculty of Medicine, Chulalongkorn University (grant number RA63/035) and the 90th Anniversary Chulalongkorn University Fund (Ratchadaphiseksomphot Endowment Fund), Graduate School, Chulalongkorn University (grant number GCUGR1125631037D-37).

Institutional Review Board Statement: All experimental procedures were in accordance with institutional guidelines and approved by the Chulalongkorn University Animal Care and Use Committee (Animal Use Protocol No. 1773011) and the Animal Ethical Committee of the Faculty of Medicine (010/2562), Chulalongkorn University, Bangkok, Thailand, in July 2018.

Informed Consent Statement: Not applicable.

Data Availability Statement: Not applicable.

Acknowledgments: We are grateful to the Research Affairs, Faculty of Medicine, Chulalongkorn University, for assistance regarding the transmission electron microscope. We thank Anucha Sacharoen (Faculty of Dentistry, Mahidol University) for his transmission electron microscopic experience. We wish to thank Surangrat Thongkorn, Kasidit Kasitipradit, Pattanachat Lertpeerapan, Pawinee Panjabud, Kwanjira Songsritaya, Wasana Yuwattana and Thanit Saeliw for their assistance in animal treatment. We also wish to acknowledge Suwanakiet Sawangkoon, Anusak Kijtawornrat, Nitira Anakkul, Choopet Nitsakulthong, Sornsawan Chumjai, Saifon Sreechomphoe and Phanupong Dungkhokkruat of the Chulalongkorn University Laboratory Animal Center for their assistance with the ethical approval process and training in the proper care and use of laboratory animals. Animal 
husbandry and housing were financially supported by Chulalongkorn University Laboratory Animal Center (CULAC) Grant (Animal Use Protocol No. 2073011) to T.S.

Conflicts of Interest: The authors declare no conflict of interest.

\section{References}

1. Gould, J.C.; Leonard, L.S.; Maness, S.C.; Wagner, B.L.; Conner, K.; Zacharewski, T.; Safe, S.; McDonnell, D.P.; Gaido, K.W. Bisphenol A interacts with the estrogen receptor alpha in a distinct manner from estradiol. Mol. Cell. Endocrinol. 1998, 142, 203-214. [CrossRef]

2. Campanale, C.; Massarelli, C.; Savino, I.; Locaputo, V.; Uricchio, V.F. A detailed review study on potential effects of microplastics and additives of concern on human health. Int. J. Environ. Res. Public Health 2020, 17, 1212. [CrossRef]

3. Takahashi, O.; Oishi, S. Disposition of orally administered 2,2-Bis(4-hydroxyphenyl)propane (Bisphenol A) in pregnant rats and the placental transfer to fetuses. Environ. Health Perspect. 2000, 108, 931-935. [CrossRef]

4. $\quad$ Cabaton, N.J.; Wadia, P.R.; Rubin, B.S.; Zalko, D.; Schaeberle, C.M.; Askenase, M.H.; Gadbois, J.L.; Tharp, A.P.; Whitt, G.S.; Sonnenschein, C.; et al. Perinatal exposure to environmentally relevant levels of bisphenol A decreases fertility and fecundity in CD-1 mice. Environ. Health Perspect. 2011, 119, 547-552. [CrossRef] [PubMed]

5. Rubin, B.S.; Murray, M.K.; Damassa, D.A.; King, J.C.; Soto, A.M. Perinatal exposure to low doses of bisphenol A affects body weight, patterns of estrous cyclicity, and plasma LH levels. Environ. Health Perspect. 2001, 109, 675-680. [CrossRef]

6. Jindatip, D.; Poh, R.W.; Fujiwara, K. Insight into the Characteristics of novel desmin-immunopositive perivascular cells of the anterior pituitary gland using transmission and focused ion beam scanning electron microscopy. Int. J. Mol. Sci. 2021, $22,8630$. [CrossRef]

7. Soji, T.; Herbert, D.C. Intercellular communication between rat anterior pituitary cells. Anat. Rec. 1989, 224, 523-533. [CrossRef] [PubMed]

8. Fujiwara, K.; Jindatip, D.; Kikuchi, M.; Yashiro, T. In situ hybridization reveals that type I and III collagens are produced by pericytes in the anterior pituitary gland of rats. Cell Tissue Res. 2010, 342, 491-495. [CrossRef]

9. Tsukada, T.; Yoshida, S.; Kito, K.; Fujiwara, K.; Yako, H.; Horiguchi, K.; Isowa, Y.; Yashiro, T.; Kato, T.; Kato, Y. TGF $\beta$ signaling reinforces pericyte properties of the non-endocrine mouse pituitary cell line TtT/GF. Cell Tissue Res. 2018, 371, 339-350. [CrossRef] [PubMed]

10. Ilmiawati, C.; Horiguchi, K.; Fujiwara, K.; Yashiro, T. Matrix metalloproteinase-9 expression in folliculostellate cells of rat anterior pituitary gland. J. Endocrinol. 2012, 212, 363-370. [CrossRef]

11. Azuma, M.; Tofrizal, A.; Maliza, R.; Batchuluun, K.; Ramadhani, D.; Syaidah, R.; Tsukada, T.; Fujiwara, K.; Kikuchi, M.; Horiguchi, K.; et al. Maintenance of the extracellular matrix in rat anterior pituitary gland: Identification of cells expressing tissue inhibitors of metalloproteinases. Acta Histochem. Cytochem. 2015, 48, 185-192. [CrossRef] [PubMed]

12. Elswefy, S.E.; Abdallah, F.R.; Atteia, H.H.; Wahba, A.S.; Hasan, R.A. Inflammation, oxidative stress and apoptosis cascade implications in bisphenol A-induced liver fibrosis in male rats. Int. J. Exp. Pathol. 2016, 97, 369-379. [CrossRef]

13. Belcher, S.M.; Gear, R.B.; Kendig, E.L. Bisphenol A alters autonomic tone and extracellular matrix structure and induces sex-specific effects on cardiovascular function in male and female CD-1 mice. Endocrinology 2015, 156, 882-895. [CrossRef]

14. Brannick, K.E.; Craig, Z.R.; Himes, A.D.; Peretz, J.R.; Wang, W.; Flaws, J.A.; Raetzman, L.T. Prenatal exposure to low doses of bisphenol A increases pituitary proliferation and gonadotroph number in female mice offspring at birth. Biol. Reprod. $2012,87,82$. [CrossRef] [PubMed]

15. Molina, A.; Abril, N.; Morales-Prieto, N.; Monterde, J.; Ayala, N.; Lora, A.; Moyano, R. Hypothalamic-pituitary-ovarian axis perturbation in the basis of bisphenol A (BPA) reproductive toxicity in female zebrafish (Danio rerio). Ecotoxicol. Environ. Saf. 2018, 156, 116-124. [CrossRef]

16. Ahmed, R.G. Maternal bisphenol A alters fetal endocrine system: Thyroid adipokine dysfunction. Food Chem. Toxicol. 2016, 95, 168-174. [CrossRef] [PubMed]

17. Katoh, K.; Matsuda, A.; Ishigami, A.; Yonekura, S.; Ishiwata, H.; Chen, C.; Obara, Y. Suppressing effects of bisphenol A on the secretory function of ovine anterior pituitary cells. Cell Biol. Int. 2004, 28, 463-469. [CrossRef]

18. Jindatip, D.; Fujiwara, K.; Horiguchi, K.; Tsukada, T.; Kouki, T.; Yashiro, T. Changes in fine structure of pericytes and novel desmin-immunopositive perivascular cells during postnatal development in rat anterior pituitary gland. Anat. Sci. Int. 2013, 88, 196-203. [CrossRef]

19. Jindatip, D.; Fujiwara, K.; Sarachana, T.; Mutirangura, A.; Yashiro, T. Characteristics of pericytes in diethylstilbestrol (DES)induced pituitary prolactinoma in rats. Med. Mol. Morphol. 2018, 51, 147-155. [CrossRef]

20. Steinmetz, R.; Brown, N.G.; Allen, D.L.; Bigsby, R.M.; Ben-Jonathan, N. The environmental estrogen bisphenol A stimulates prolactin release in vitro and in vivo. Endocrinology 1997, 138, 1780-1786. [CrossRef]

21. Ulbrich, S.E.; Kettler, A.; Einspanier, R. Expression and localization of estrogen receptor alpha, estrogen receptor beta and progesterone receptor in the bovine oviduct in vivo and in vitro. J. Steroid Biochem. Mol. Biol. 2003, 84, 279-289. [CrossRef]

22. Hao, L.; Zhang, J.; Zhang, Y.; Hu, H.; Shao, W.; Zhang, X.; Geng, C.; Wang, Y.; Jiang, L. Effect of bisphenol a on occurrence and progression of prolactinoma and its underlying mechanisms. Am. J. Transl. Res. 2016, 8, 4195-4204. [PubMed] 
23. Wada, I.; Sakuma, E.; Shirasawa, N.; Wakabayashi, K.; Otsuka, T.; Hattori, K.; Yashiro, T.; Herbert, D.C.; Soji, T. Intercellular communications within the rat anterior pituitary. XVI: Postnatal changes of distribution of S-100 protein positive cells, connexin 43 and LH-RH positive sites in the pars tuberalis of the rat pituitary gland. An immunohistochemical and electron microscopic study. Tissue Cell 2014, 46, 33-39. [CrossRef] [PubMed]

24. Fujiwara, K.; Tsukada, T.; Horiguchi, K.; Fujiwara, Y.; Takemoto, K.; Nio-Kobayashi, J.; Ohno, N.; Inoue, K. Aldolase C is a novel molecular marker for folliculo-stellate cells in rodent pituitary. Cell Tissue Res. 2020, 381, 273-284. [CrossRef]

25. Mitchner, N.A.; Garlick, C.; Ben-Jonathan, N. Cellular distribution and gene regulation of estrogen receptors alpha and beta in the rat pituitary gland. Endocrinology 1998, 139, 3976-3983. [CrossRef]

26. Fauquier, T.; Rizzoti, K.; Dattani, M.; Lovell-Badge, R.; Robinson, I.C. SOX2-expressing progenitor cells generate all of the major cell types in the adult mouse pituitary gland. Proc. Natl. Acad. Sci. USA 2008, 105, 2907-2912. [CrossRef]

27. Yoshida, S.; Kato, T.; Yako, H.; Susa, T.; Cai, L.Y.; Osuna, M.; Inoue, K.; Kato, Y. Significant quantitative and qualitative transition in pituitary stem / progenitor cells occurs during the postnatal development of the rat anterior pituitary. J. Neuroendocrinol. 2011, 23, 933-943. [CrossRef]

28. Andoniadou, C.L.; Matsushima, D.; Mousavy Gharavy, S.N.; Signore, M.; Mackintosh, A.I.; Schaeffer, M.; Gaston-Massuet, C.; Mollard, P.; Jacques, T.S.; Le Tissier, P.; et al. Sox2(+) stem/progenitor cells in the adult mouse pituitary support organ homeostasis and have tumor-inducing potential. Cell Stem Cell 2013, 13, 433-445. [CrossRef]

29. Brokken, L.J.; Leendertse, M.; Bakker, O.; Wiersinga, W.M.; Prummel, M.F. Expression of adenohypophyseal-hormone receptors in a murine folliculo-stellate cell line. Horm. Metab. Res. 2004, 36, 538-541. [CrossRef]

30. Brokken, L.J.; Bakker, O.; Wiersinga, W.M.; Prummel, M.F. Functional thyrotropin receptor expression in the pituitary folliculostellate cell line TtT/GF. Exp. Clin. Endocrinol. Diabetes 2005, 113, 13-20. [CrossRef]

31. Chen, G.; Ge, D.; Zhu, B.; Shi, H.; Ma, Q. Upregulation of matrix metalloproteinase 9 (MMP9)/tissue inhibitor of metalloproteinase 1 (TIMP1) and MMP2/TIMP2 ratios may be involved in lipopolysaccharide-induced acute lung injury. J. Int. Med. Res. 2020, 48, 300060520919592. [CrossRef] [PubMed]

32. Savabieasfahani, M.; Kannan, K.; Astapova, O.; Evans, N.P.; Padmanabhan, V. Developmental programming: Differential effects of prenatal exposure to bisphenol-A or methoxychlor on reproductive function. Endocrinology 2006, 147, 5956-5966. [CrossRef] [PubMed]

33. Thongkorn, S.; Kanlayaprasit, S.; Jindatip, D.; Tencomnao, T.; Hu, V.W.; Sarachana, T. Sex Differences in the Effects of Prenatal Bisphenol A Exposure on Genes Associated with Autism Spectrum Disorder in the Hippocampus. Sci. Rep. 2019, 9, 3038. [CrossRef]

34. Sukjamnong, S.; Thongkorn, S.; Kanlayaprasit, S.; Saeliw, T.; Hussem, K.; Warayanon, W.; Hu, V.W.; Tencomnao, T.; Sarachana, T. Prenatal exposure to bisphenol A alters the transcriptome-interactome profiles of genes associated with Alzheimer's disease in the offspring hippocampus. Sci. Rep. 2020, 10, 9487. [CrossRef] [PubMed]

35. Thongkorn, S.; Kanlayaprasit, S.; Panjabud, P.; Saeliw, T.; Jantheang, T.; Kasitipradit, K.; Sarobol, S.; Jindatip, D.; Hu, V.W.; Tencomnao, T.; et al. Sex differences in the effects of prenatal bisphenol A exposure on autism-related genes and their relationships with the hippocampus functions. Sci. Rep. 2021, 11, 1241. [CrossRef] 